\title{
Research on College English Language and Culture Teaching Mode
}

\author{
Aili Cheng \\ Hubei University of Chinese Medicine, Wuhan, Hubei, 430060
}

Keywords: college English; cross-cultural; teaching mode

\begin{abstract}
As the most widely used universal language in the world, English is regarded as a second foreign language by most countries and plays an important role in international communication. Today, higher education is in line with international standards, and most professional courses take bilingual teaching mode. Therefore, learning English is particularly important. The new curriculum reform also puts forward a higher requirement for college English education. It is pointed out that college English should be based on English language knowledge and application skills, learning strategies and cross-cultural communication, and guided by the new foreign language teaching theory. A variety of teaching modes and teaching methods are combined to form an English teaching system. Traditional English teaching uses language as the tool, while the new curriculum reform emphasizes that language is a part of cultural composition and that the cross-cultural communication ability of undergraduates should be improved through teaching. Therefore, college English teaching should pay more attention to the attribute of English as the carrier of cultural inheritance. Based on the basic knowledge of English master by students, students should improve their understanding of English and American culture and teachers are required to develop students with intercultural communication skills to become talented people with a new era of international cultural vision.
\end{abstract}

\section{Introduction}

In today's society, the rapid development of the Internet has made the exchanges between peoples around the world more convenient. With the popularization of various types of translation software and artificial intelligence, languages can no longer solve all problems. Culture has become one of the important factors in international communication. Therefore, today's internationalization of higher education, college English teaching, while teaching language skills, should also pay attention to cultural teaching, allowing students to broaden their horizons through the study of foreign culture, promote innovation and enhance cultural taste [1].

In the 1960s, western countries had realized the importance of cross-cultural language teaching and established the position of cultural teaching in higher education. In the 1980s, cross-cultural teaching became the focus of English teaching. In contrast, China's cross-cultural language teaching started late, but in the 1980s it also pointed out that long-term English teaching in the country only focuses on vocabulary and ignores the need for cultural exchange. At the end of last century, many domestic scholars pointed out this issue. The close relationship between culture and language, and proposed that cross-cultural education should be applied to English teaching [2].

The necessity of cross-cultural English teaching is mainly reflected in the following aspects: 1 It helps to improve the English ability of college students. Language is the carrier of national culture. Although it can achieve the purpose of simple communication from the point of view of language, it is difficult to apply appropriate language, and Chinese-style English will appear. It is also difficult to understand the deeper level of consciousness in the other party's speech due to different cultural connotations, and it is difficult to integrate into the group to gain social happiness. Therefore, if there are linguistic knowledge and cultural barriers in both sides of the communication, the large and small language expression problems in the exchange process may give the other party a bad impression. In teaching, while paying attention to the structure and form of language, we must also pay attention to the combination of language teaching and cross-cultural teaching. We should talk about English expression and use in a specific cultural context so that students can fully understand 
the culture and enable students to interact in different environments and topics. Under the cultural background, we can express correctly and use the language flexibly to become a comprehensive English talent. 2 Promoting cultural exchange is also a need to promote local culture. The ultimate goal of language learning is to understand the meaning of both parties in the process of communication. Therefore, the focus of teaching should be to improve the ability of language communication. Students understand their national cultural connotations through foreign language materials. In this process, they can also feel the difference between the target language and local culture, strengthen their understanding of their own national culture, seek common ground while reserving differences, and form an independent personality and high cultural accomplishment. In the international stage exchanges, the ethnic culture is promoted in an appropriate manner and the national spirit is promoted. 3 Conform to the needs of international education. With the further development of economic globalization and integration, dialogue and exchanges between countries and organizations in the country and the world will greatly promote economic development. English is also the carrier of advanced technological exchanges worldwide. Scientists from all over the world express their new achievements and discoveries in English. Therefore, while teaching English language skills, English teaching should also pay attention to the introduction of culture, and cultivate comprehensive talents from transnational and trans-regional areas. This has positive significance for international exchanges and scientific and technological exchanges [3].

\section{Problems and Causes in English Teaching in China}

The English level of most people in our country is dumb English or fluent but it cannot express the meaning correctly. Cross-cultural language teaching also has many problems: 1 The goal of cross-cultural teaching is not clear. Nowadays, the ability of college students to use English has been greatly improved compared with the past. However, there are still certain problems in reading and writing, such as low vocabulary, daily vocabulary and other activities of people in countries with native English speakers. Compared with the requirements of the second foreign language countries, the gap is still relatively large. The ability to use English is low. After completing university public English during college, non-English majors will basically no longer accept English-related courses. The goal of setting college English teaching in our country is relatively low, and the ability to cultivate students' cross-cultural communication is beyond the teaching goal. Many teachers do not have a deep understanding of foreign cultures, and only stay at the level of knowing the customs and customs of foreign countries and customs, and it is difficult to explain to students clearly the connotation of culture and the development of English use [4]. 2 Cross-cultural teaching resources are scarce. The English syllabus proposes teaching requirements to improve students' cultural quality, but it does not form a complete teaching system. When teachers teach, they only explain some cross-cultural knowledge in a scattered manner, and they have no system to speak of. Students may remember trivial content, but most of the content will be forgotten in a very short period of time. Therefore, it is difficult for students to understand the importance of culture for language. Simply treating those as small knowledge or customs does not significantly improve students' ability to communicate across cultures. College English textbooks only introduce the social background and some of the apparent cultural content, lack of cross-cultural knowledge. Chinese culture is also difficult to see in the teaching materials. This is unfavorable for the improvement of college students' English communication skills and the successful completion of cross-cultural communication. 3 Teaching methods are backward. Classroom teaching methods do not give full play to the students' main role, and new teaching methods such as the cognitive method and the communicative method have not yet been popularized. The university classroom is still focused on vocabulary usage, grammar, and translation. It does not have a guiding role in students' correct reading and understanding of materials, and in the development of cross-cultural knowledge and cross-cultural abilities [5]. Indoctrination teaching makes students lose interest in English and enthusiasm for learning to further make students feel disgusted with language teaching.

The main reasons for the existence of these problems are as follows: The teachers themselves are culturally indifferent and lack cultural knowledge. Under the influence of traditional education 
ideas, they only pay attention to the teaching of English language knowledge and forms. The depth of cross-cultural teaching theory in China is not enough to form a scientific and effective method and promote it. Lack of policy orientation, the teacher's explanation is also based on self-understanding simply explain the cultural background related knowledge, it is difficult to explain the culture in-depth. All of these have led to a lack of understanding of cross-cultural knowledge among students. Although they like to watch American dramas, they also only stay at the level of the plots. They lack proper guidance and lack further understanding of culture. Some students even lack the initiative to learn English. They only take English as a course or a stepping stone according to the examination requirements, graduation requirements, or job-hunting needs. Therefore, they do not attach importance to the deep-level learning of other cultures [6]. Chinese college students have long been under the traditional educational method of spoon-feeding and attached more importance to the examination results. Most of the thinking methods and values formed in this way lack cultural heritage. When learning western cultural ideas, it is even more difficult to grasp them correctly. If the problems are not comprehensive and the essence cannot be grasped, there will be a phenomenon of admiration and fascination. This is a study of traditional culture. The understanding of other countries' cultures is unfavorable. It is impossible to see the true differences between cultures, and it is even more difficult to form cross-cultural communication skills.

\section{Strategies to Improve Cross-cultural English Teaching}

The teaching goal of cross-cultural teaching of college English should be based on cultivating students' language knowledge and strengthening students' communicative competence and cross-cultural communication ability. While teaching students vocabulary use and grammar norms, they also focus on explaining culture, designing practical activities, and effectively improving students' cross-cultural cognition. This will help students have a solid foundation in English and have the ability to communicate with people in different cultures [7]. It is also possible to further understand the regularity and composition of the two languages through the same and differences between the foreign language and the mother tongue.

In the teaching process, the basic principles of integration of cultural teaching and language teaching should be followed. Students should be the subject of the class, and various methods and means should be used to guide students according to their characteristics. Students should find their own learning mode and strengthen the process of independent learning. . In class, teachers should pay attention to the process of interaction with students and develop English cross-cultural teaching in the process. Rationally use the Internet to guide student learning, form an interactive teaching mode, strengthen video and audio guidance teaching, and achieve online and offline teaching integration. Students can use the Internet to study at any time, teachers can answer questions on line at a fixed time, and communicate offline to improve students' enthusiasm for learning English. Schools can also try to build cross-cultural communication courses as a supplement to basic English courses to help students improve cross-cultural language skills. It is also possible to use bilingual teaching in specialized courses and cultural classes to make the boring traditional classrooms become active, students' learning status from passive to active, to improve students' interest in English and to enhance the effectiveness of cross-cultural teaching [8]. All-British teaching can also be used to provide an immersive learning environment. Focus on the use of micro-curriculum resources and Internet chat tools. Students watch micro-curriculums. The content can be related to American dramas or news on topics of interest to the students. It also explains the cultural content involved, and cultivates students' independent learning ability and interest in learning. After the students can also choose videos of different subjects according to their own interests, as entertainment to watch, encounter interesting places to find information, starting from interest, in the music school.

Diversified teaching methods can be used to increase the interactivity and fun of the curriculum [9]. For example, if a sitcom assignment is arranged according to a topic, the students form a group on their own, collect material, write a script, and perform. In the process, they can deepen cultural 
understanding, strengthen group cooperation and communication, and improve the ability to use language. In performances, we should pay attention to modality and discourse, etc. While others are watching carefully, they must provide opinions on irrationalities or places that can be improved. By analyzing the cultural phenomena and conflicts in the play, strengthen the ability of cultural analysis. If conditions do not allow, dialogues and exchanges can also be arranged. Although they lack some interesting features, they can also improve cultural learning and language use. You can learn idioms in different situations and analyze the internal values. You can arrange lectures or presentations to help students analyze the characteristics and ways of doing things in Chinese culture and Western culture from a certain point, compare the similarities and differences between the cultures of the two countries, and try to analyze the causes of these differences based on geographical or historical reasons. Experience different cultural differences.

\section{Conclusion}

To sum up, in order to comply with international economic trends and educational development trends, Chinese college English teaching should aim at improving students' cultural understanding and communication skills as their important goals in English teaching. Clear teaching objectives, reform and innovation of traditional teaching methods, and focus on cross-cultural teaching. English teaching does not only focus on vocabulary and grammar, but also adopts a variety of means and teaching methods, focusing on the combination of language and culture teaching.

\section{References}

[1] Tian Xiaoyu. Research on Intercultural Teaching of College English under the Background of Higher Education Internationalization[J]. Journal of Liaoning Education Administration Institute, 2017, 34(03):55-58.

[2] Zhang Xiaoyan. Research status quo and theoretical considerations in the construction of college English intercultural teaching model[J]. Contemporary Educational Practice and Teaching Research, 2016(12):53.

[3] Liu Anhong. Research on the cultivation of intercultural communicative competence in college English under multimodal interactive teaching mode[J]. Journal of Chongqing University of Arts and Sciences (Social Sciences Edition), 2017, 36(03): 88-91.

[4] Li Ying. Research on mixed teaching mode of college English based on flipped classroom[J]. Journal of Liaoning University of Technology (Social Sciences Edition), 2016, 18(06):115-118.

[5] Li Songhua. Research on College English Teaching Model from the Perspective of Cross-cultural Communication[J]. Journal of Suzhou Education Institute, 2015, 18(06):121-122+125.

[6] Cai Yun. Research on the Construction of English Teaching Model in China's Universities under the Perspective of Cross-cultural Perspective [J]. Asia-Pacific Education, 2016(03):69.

[7] Xu Huijuan, Cao Jun, Jiang Daohua. Cultivation of Undergraduates' Self-learning Ability under Cross-cultural English Teaching Model: A New Approach to College English Teaching [J]. Journal of Suzhou University, 2013, 28(12): 117-120.

[8] Zhu Hongmei, GENG. Cultural transformation and teaching networkization of college English teaching reform supported by modern technology: A case study of Beijing Forestry University [J]. Chinese Journal of Forestry Education, 2017, 35(01):76-78.

[9] Chen Qun. Research on College English Language and Culture Teaching Model [J]. China Hi-tech Zone, 2017(14):52. 